\title{
Diaphragmatic Eventration Secondary to Ectopic Kidneys
}

\author{
Deng-Wei Chou and Yeun Tarl Fresner Ng Jao
}

Key words: diaphragmatic eventration, ectopic kidney

(Intern Med 53: 2017-2018, 2014)

(DOI: 10.2169/internalmedicine.53.2492)

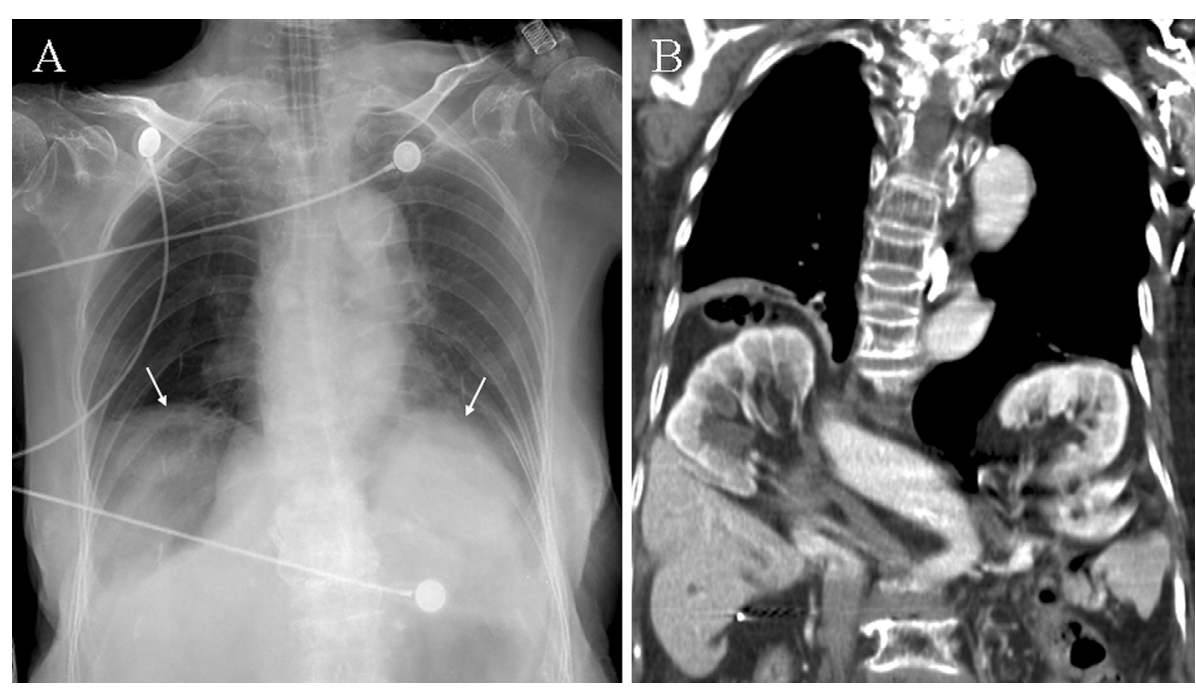

Picture 1.
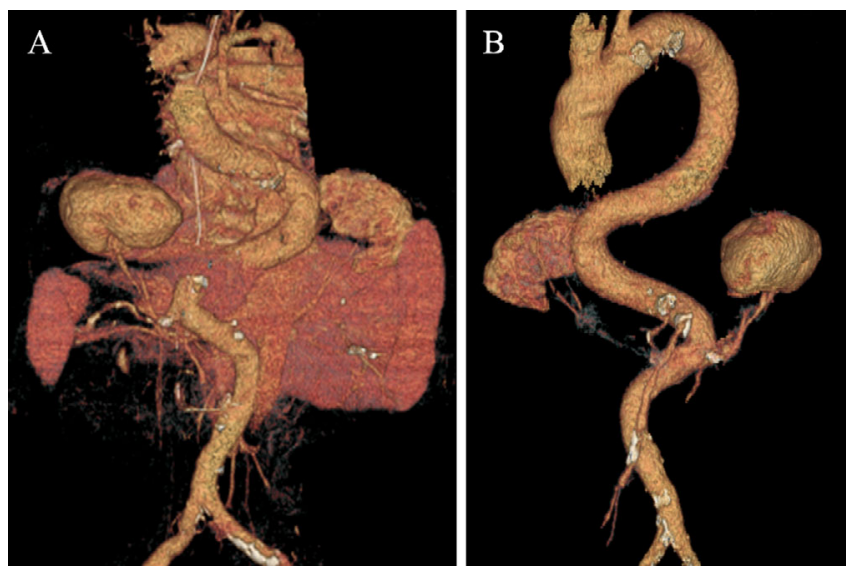

Picture 2.

A 94-year-old woman presented to our emergency department with dyspnea after choking on food. She was immediately intubated and given ventilator support due to hypoxemia. Following intubation, a supine chest radiograph showed marked elevation of the bilateral hemidiaphragm (Picture 1 A, arrows). In addition, there was a well-circumscribed area of radio-opacity measuring approximately $8 \mathrm{~cm}$ over the retrocardiac region. A contrast-enhanced computed to- 
mographic scan revealed diaphragmatic eventration secondary to ectopic kidneys bilaterally (Picture 1B, coronal section). Three-dimensional reconstruction of the images showed the right kidney to be situated above the liver, with the left kidney located above the spleen (Picture 2A, dorsal view). However, both renal arteries were found to be in their normal locations, originating below the celiac artery from the aorta (Picture 2B, oblique view). The patient's serum creatinine level was $1.0 \mathrm{mg} / \mathrm{dL}$ and a urinalysis disclosed mild proteinuria without pyuria. Due to her deteriorated condition, her family signed a "do-not-resuscitate" form. Eventually, the patient died due to aspiration pneumonia that progressed to septic shock.

The authors state that they have no Conflict of Interest (COI).

(C) 2014 The Japanese Society of Internal Medicine http://www.naika.or.jp/imonline/index.html 